\title{
Estimation of the depth of the thoracic epidural space in children using magnetic resonance imaging
}

This article was published in the following Dove Press journal: Journal of Pain Research

28 March 2017

Number of times this article has been viewed

\author{
Tariq MWani',2 \\ Mahmood Rafiq' \\ Arif Nazir' \\ Hatem A Azzam' \\ Usama Al Zuraigi' \\ Joseph D Tobias ${ }^{2}$
}

'Department of Anesthesia, King Fahad Medical City, Riyadh, Saudi Arabia; 'Department of Anesthesiology and Pain Medicine, Nationwide Children's Hospital, Columbus, $\mathrm{OH}$, USA
Correspondence: Tariq M Wani Department of Anesthesia, King Fahad Medical City, Riyadh I I525, Saudi Arabia Email tariqwani@gmail.com
Background: The estimation of the distance from the skin to the thoracic epidural space or skin to epidural depth (SED) may increase the success rate and decrease the incidence of complications during placement of a thoracic epidural catheter. Magnetic resonance imaging (MRI) is the most comprehensive imaging modality of the spine, allowing for the accurate determination of tissue spaces and distances. The present study uses MRI-derived measurements to measure the SED and define the ratio between the straight and inclined SEDs at two thoracic levels $\left(\mathrm{T}_{6-7}\right.$ and $\mathrm{T}_{9-10}$ ) in children.

Methods: The $\mathrm{T}_{2}$-weighed sagittal MRI images of 109 children, ranging in age from 1 month to 8 years, undergoing radiological evaluation unrelated to spine pathology were assessed. The SEDs (inclined and straight) were determined, and a comparison between the SEDs at two thoracic levels $\left(\mathrm{T}_{6-7}\right.$ and $\left.\mathrm{T}_{9-10}\right)$ was made. Univariate and multivariate linear regression models were used to assess the relationship of the inclined thoracic $T_{6-7}$ and $T_{9-10}$ SED measurements with age, height, and weight.

Results: Body weight demonstrated a stronger association with the SED than did the age or height with $R^{2}$ values of 0.6 for $\mathrm{T}_{6-7}$ and 0.5 for $\mathrm{T}_{9-10}$. The formulae describing the relationship between the weight and the inclined SED were $\mathrm{T}_{6-7}$ inclined $(\mathrm{mm})=7+0.9 \times \mathrm{kg}$ and $\mathrm{T}_{9-10}$ inclined $(\mathrm{mm})=7+0.8 \times \mathrm{kg}$.

Conclusion: The depth of the pediatric thoracic epidural space shows a stronger correlation with weight than with age or height. Based on the MRI data, the predictive weight-based formulas can serve as guide to clinicians for placement of thoracic epidural catheters.

Keywords: thoracic epidural space, magnetic resonance imaging, measurement techniques

\section{Introduction}

Epidural anesthesia/analgesia in children has increased in popularity over the past 20 years, with a very low rate of complications following direct thoracic placement. ${ }^{1-3}$ In addition to providing effective analgesia following major thoracic and upper abdominal procedures, it may offer compelling physiologic advantages over systemic opioid analgesia in infants and children, including a reduced need for postoperative ventilatory support, improved analgesia without the risk of opioid-induced respiratory depression, and improved control of the surgical stress response. ${ }^{4-10}$

Direct placement of a thoracic epidural catheter in the pediatric-aged patient may be technically challenging due to compliant soft tissues/ligaments as well as shallow and variable distances from the skin to the epidural space. The prediction of the actual depth of the thoracic epidural space or the skin to epidural depth (SED) may increase the success rate and improve the safety of epidural procedures. ${ }^{11,12}$ The SED varies 
depending on the vertebral level, patient characteristics, including age and weight, and the angle of needle entry for puncture. ${ }^{13}$ The SED in children has been derived mainly from direct needle measurements after entry into the epidural space, computed tomography (CT) imaging, magnetic resonance imaging (MRI), and ultrasonography. ${ }^{13-15}$

MRI is highly sensitive for identifying injuries to the posterior longitudinal ligament and interspinous soft tissues when compared to $\mathrm{CT}$ imaging and remains the method of choice for assessing spinal cord lesions and ligamentous injury. ${ }^{16-18}$ Since MRI is the most comprehensive imaging modality of the paraspinal and intraspinal soft tissues and ligaments, the measurements derived may be more accurate and thereby provide a useful tool to derive the SED. The primary objective of the current study was to derive a formula from MRI-based data for predicting the SED in infants and children. The secondary aim was to evaluate potential differences in the SED at various thoracic levels and to determine how changes in the needle approach (straight versus inclined) may affect these measurements.

\section{Methods}

A database search of the electronic medical records identified MRI examinations of the lumbar and thoracic spine performed in children up to 8 years of age. The institutional review board (IRB) of King Fahad Medical City approved the study. Informed consent was waived by the IRB on the basis that it was a retrospective study where the collection of radiological data was based on deidentified patients by the archive department only. Exclusion criteria included any diagnosis or condition that the investigators felt would cause abnormal spinal anatomy or interfere with the measurements obtained during MRI. Patients with scoliosis, tethered cord, spina bifida, myelomeningocele, tumors of the spinal cord or vertebral bodies, spinal metastatic disease, and those outside the 10th-90th percentile of weight-for-age based on World Health Organization growth standards were excluded from the study. Patients with poor image quality were also excluded.

Using an internal measurement device, sagittal $\mathrm{T}_{2}$-weighted imaging of the thoracic spine was used to measure the SED (distance from the skin edge to the dural side of the ligamentum flavum) at the $\mathrm{T}_{6-7}$ and $\mathrm{T}_{9-10}$ interspaces. At each level, two measurements were taken. The first measurement was taken perpendicular to the long axis of the vertebral body. The second measurement (inclined) was taken between the spinous processes with the measurement parallel to the spinous processes (Figures 1 and 2). Measurements

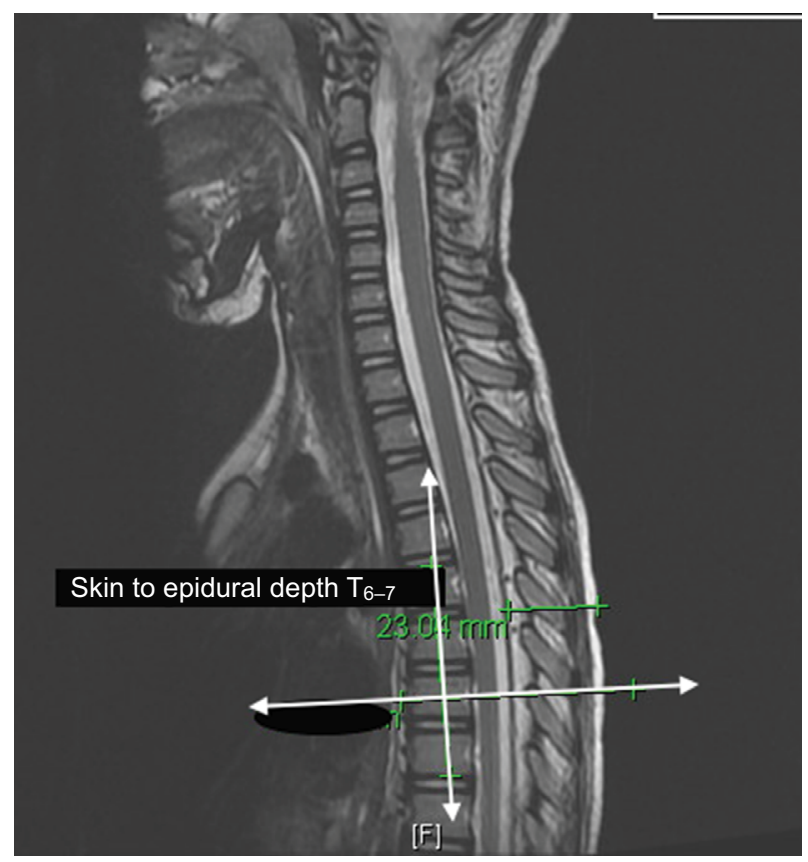

Figure I Magnetic resonance image of the thoracic spine and vertebral bodies showing technique for the measurement of the perpendicular skin to epidural distance at the $\mathrm{T}_{6-7}$ interspace.

Note: The measurement was taken perpendicular to the long axis of the vertebral body (dark lines).

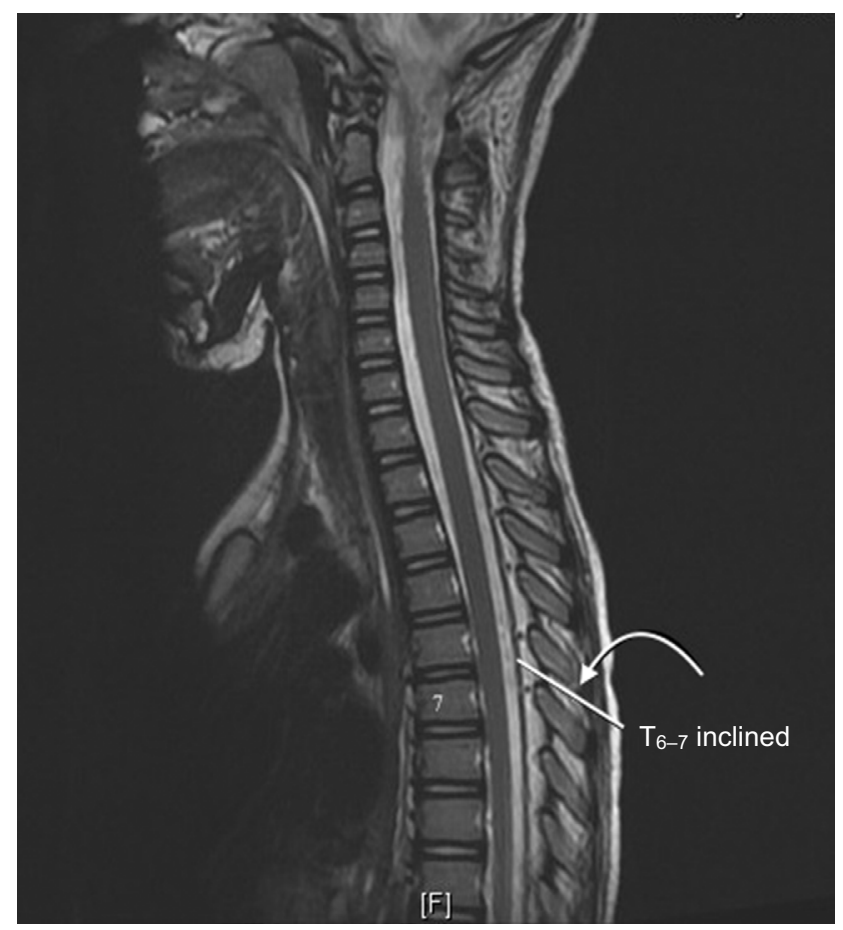

Figure 2 Magnetic resonance image of the thoracic spine and vertebral bodies showing technique for the measurement of the inclined skin to epidural depth at the $T_{6-7}$ interspace.

Note: The measurement (inclined) was taken between and parallel to the spinous processes.

were taken by two of the authors ( $\mathrm{AN}$ and $\mathrm{AH}$ ) independent of each other and verified by a coauthor. The measurement used was the mean distance of both observers (MR). All 
authors subsequently reviewed any discrepancy between the measurements. All investigators were blinded to the age of the patients until measurements were analyzed.

\section{Statistical analysis}

All analyses were performed using SPSS. Group comparisons were performed using independent samples $t$-tests after verifying approximate normality and equality of group variances. Univariate and multivariate linear regression models were used to assess the relationship of the inclined thoracic $\mathrm{T}_{6-7}$ and $\mathrm{T}_{9-10}$ SED measurements with the age, height, and weight. $P<0.05$ was considered statistically significant. Coefficient of determination $\left(R^{2}\right)$ was calculated to study the predictive ability of age, height, and weight on the inclined thoracic $\mathrm{T}_{6-7}$ and $\mathrm{T}_{9-10}$ SED measurements. Confidence intervals were calculated for all the age groups. Two-sided $P$-values $<0.05$ were considered statistically significant. The ratios between inclined and straight SEDs at the two levels were analyzed.

\section{Results}

A total of 109 MRI scans of the spine in children, ranging in age from 1 month to 8 years undergoing radiological evaluation unrelated to spine pathology, were included in the study cohort. Of these 109 patients, 68 (62\%) were boys with a mean age of $46.1 \pm 16.1$ months and $41(37 \%)$ were girls with a mean age of $63 \pm 21.6$ months. The mean values and confidence intervals of inclined and straight SEDs $\left(\mathrm{T}_{6-7}\right.$ and $\mathrm{T}_{9-10}$ ) for all the age groups are listed in Table 1. No difference in the SEDs was noted based on gender (Table 2).

Using univariate analysis (Table 3), all the variables studied (age, height, and weight) showed a significant positive relationship with the SEDs at $\mathrm{T}_{6-7}$ and at $\mathrm{T}_{9-10}$ (inclined). Weight showed the strongest association with the inclined SED ( $T_{6-7}$ and $\mathrm{T}_{9-10}$ ) with $R^{2}$ values of 0.6 for inclined measurements at $\mathrm{T}_{6-7}$ and 0.5 for inclined measurements at $\mathrm{T}_{9-10}$ (Figures 3 and 4). In the multivariate regression analysis (Table 4), weight was the only variable that predicted the inclined SED $\left(\mathrm{T}_{6-7}\right.$ and $\mathrm{T}_{9-10}$ ) independently with $P<0.05$ and $R^{2}=0.5$. Age and weight did not contribute to a further reduction in the variance of the inclined SED at $\mathrm{T}_{6-7}$ or $\mathrm{T}_{9-10}$ (Figures 3 and 4 ). The data demonstrated a well-defined relationship between the weight and the inclined SED at $\mathrm{T}_{6-7}$ and $\mathrm{T}_{9-10}$. Based on these data, the following formulas were developed:

$$
\begin{aligned}
& \mathrm{T}_{6-7} \text { inclined }(\mathrm{mm})=7+0.9 \times \mathrm{kg} \\
& \mathrm{T}_{9-10} \text { inclined }(\mathrm{mm})=7+0.8 \times \mathrm{kg}
\end{aligned}
$$

\begin{tabular}{|c|c|c|c|c|}
\hline \multirow[t]{2}{*}{ Age (years) } & \multirow[t]{2}{*}{ Level } & \multirow[t]{2}{*}{$\begin{array}{l}\text { Mean } \pm \text { SD } \\
(\mathrm{mm})\end{array}$} & \multicolumn{2}{|c|}{$\begin{array}{l}95 \% \text { Confidence } \\
\text { interval }\end{array}$} \\
\hline & & & $\begin{array}{l}\text { Lower } \\
(\mathrm{mm})\end{array}$ & $\begin{array}{l}\text { Upper } \\
(\mathrm{mm})\end{array}$ \\
\hline \multirow[t]{4}{*}{$0-I(n=4)$} & $T_{6-7}$ straight & $13.9 \pm 3.2$ & 8.9 & 17.3 \\
\hline & $T_{6-7}$ inclined & $15.6 \pm 2.9$ & II.I & 20.2 \\
\hline & $T_{9-10}$ straight & $13.7 \pm 2.8$ & 9.6 & 17.9 \\
\hline & $T_{9-10}$ inclined & $15.1 \pm 2.7$ & 10.9 & 19.3 \\
\hline \multirow[t]{4}{*}{$I-2(n=5)$} & $\mathrm{T}_{6-7}$ straight & $16.7 \pm 1.9$ & 10.9 & 22.5 \\
\hline & $T_{6-7}$ inclined & $19.5 \pm 2.1$ & 13.4 & 25.5 \\
\hline & $T_{9-10}$ straight & $15.8 \pm 1.5$ & 9.9 & 21.6 \\
\hline & $T_{9-10}$ inclined & $18.5 \pm 1.8$ & 11.3 & 25.7 \\
\hline \multirow[t]{4}{*}{$2-3(n=13)$} & $\mathrm{T}_{6-7}$ straight & $16.9 \pm 1.9$ & 10.9 & 22.5 \\
\hline & $\mathrm{T}_{6-7}$ inclined & $18.5 \pm 2.1$ & 13.4 & 25.6 \\
\hline & $T_{9-10}$ straight & $16.3 \pm 1.5$ & 15.5 & 17.2 \\
\hline & $T_{9-10}$ inclined & $18.2 \pm 1.8$ & 17.1 & 19.2 \\
\hline \multirow[t]{4}{*}{$3-4(n=27)$} & $\mathrm{T}_{6-7}$ straight & $18.1 \pm 3.5$ & 16.7 & 19.5 \\
\hline & $T_{6-7}$ inclined & $20.5 \pm 3.9$ & 18.9 & 21.9 \\
\hline & $T_{9-10}$ straight & $17.1 \pm 2.9$ & 15.9 & 18.2 \\
\hline & $T_{9-10}$ inclined & $19.3 \pm 3.3$ & 17.9 & 20.6 \\
\hline \multirow[t]{4}{*}{ 4-5 (n = 2I) } & $T_{6-7}$ straight & $19.3 \pm 3.1$ & 17.9 & 20.7 \\
\hline & $T_{6-7}$ inclined & $22.1 \pm 4.1$ & 20.3 & 23.9 \\
\hline & $T_{9-10}$ straight & $18.4 \pm 2.9$ & 17.1 & 19.8 \\
\hline & $T_{9-10}$ inclined & $20.7 \pm 3.5$ & 19.1 & 22.2 \\
\hline \multirow[t]{4}{*}{$5-6(n=29)$} & $T_{6-7}$ straight & $20.1 \pm 5.1$ & 18.9 & 22.8 \\
\hline & $T_{6-7}$ inclined & $24.1 \pm 5.9$ & 21.9 & 26.3 \\
\hline & $T_{9-10}$ straight & $20.7 \pm 5$ & 18.8 & 22.6 \\
\hline & $\mathrm{T}_{9-10}$ inclined & $22.7 \pm 5.7$ & 20.1 & 24.9 \\
\hline \multirow[t]{4}{*}{$6-7(n=10)$} & $\mathrm{T}_{6-7}$ straight & $21.5 \pm 5.5$ & 17.7 & 25.4 \\
\hline & $T_{6-7}$ inclined & $27.5 \pm 10.3$ & 20.2 & 34.9 \\
\hline & $\mathrm{T}_{9-10}$ straight & $22.4 \pm 7.1$ & 17.4 & 27.5 \\
\hline & $\mathrm{T}_{9-10}$ inclined & $25.5 \pm 9.2$ & 18.9 & 32.1 \\
\hline \multirow[t]{4}{*}{$7-8(n=6)$} & $\mathrm{T}_{6-7}$ straight & $22.8 \pm 5$ & 18.7 & 27 \\
\hline & $T_{6-7}$ inclined & $28.3 \pm 8.9$ & 20.8 & 35.8 \\
\hline & $\mathrm{T}_{9-10}$ straight & $23.6 \pm 6.5$ & 18.2 & 28.9 \\
\hline & $\mathrm{T}_{9-10}$ inclined & $26.7 \pm 7.6$ & 20.4 & 32.9 \\
\hline
\end{tabular}

Table I Distribution of SED measurements by age

Abbreviations: SED, skin to epidural depth; SD, standard deviation.

\begin{tabular}{|c|c|c|c|c|c|}
\hline \multirow{2}{*}{$\begin{array}{l}\text { Level of } \\
\text { measurement } \\
\text { and incline }\end{array}$} & \multirow[t]{2}{*}{ Gender } & \multirow[t]{2}{*}{$\begin{array}{l}\text { Mean } \pm \text { SD } \\
(\mathrm{mm})\end{array}$} & \multicolumn{2}{|c|}{$\begin{array}{l}\text { 95\% Confidence } \\
\text { interval }\end{array}$} & \multirow[t]{2}{*}{$P$-value } \\
\hline & & & $\begin{array}{l}\text { Lower } \\
(\mathrm{mm})\end{array}$ & $\begin{array}{l}\text { Upper } \\
(\mathrm{mm})\end{array}$ & \\
\hline \multirow[t]{2}{*}{$\mathrm{T}_{6-7}$ straight } & Boys & $18.1 \pm 3.4$ & 17.3 & 18.9 & 0.00 \\
\hline & Girls & $20.9 \pm 5.3$ & 19.1 & 22.5 & 0.00 \\
\hline \multirow[t]{2}{*}{$T_{6-7}$ inclined } & Boys & $20.5 \pm 3.9$ & 19.6 & 21.4 & 0.00 \\
\hline & Girls & $24.5 \pm 7.3$ & 22.1 & 26.7 & 0.00 \\
\hline \multirow[t]{2}{*}{$\mathrm{T}_{9-10}$ straight } & Boys & $19.5 \pm 3.6$ & 18.7 & 20.5 & 0.00 \\
\hline & Girls & $20.8 \pm 5.3$ & 18.9 & 22.6 & 0.00 \\
\hline \multirow[t]{2}{*}{$\mathrm{T}_{9-10}$ inclined } & Boys & $19.6 \pm 3.6$ & 18.7 & 20.1 & 0.00 \\
\hline & Girls & $22.9 \pm 6.8$ & 20.8 & 25.9 & 0.00 \\
\hline
\end{tabular}

Table 2 Comparison of the SED between genders

Abbreviations: SED, skin to epidural depth; SD, standard deviation. 
Table 3 Univariate regression effects of inclined measurements of SED

\begin{tabular}{lllll}
\hline Level & Parameter & SE (mm/month) & P-value & $\boldsymbol{R}^{\mathbf{2}}$ \\
\hline $\mathrm{T}_{6-7}$ inclined & Age & 0.03 & 0.000 & 0.3 \\
& Height & 0.06 & 0.000 & 0.3 \\
& Weight & 0.16 & 0.000 & 0.6 \\
$\mathrm{~T}_{9-10}$ inclined & Age & 0.23 & 0.000 & 0.3 \\
& Height & 0.04 & 0.000 & 0.2 \\
& Weight & 0.09 & 0.000 & 0.6 \\
\hline
\end{tabular}

Abbreviations: SED, skin to epidural depth; SE, standard error.

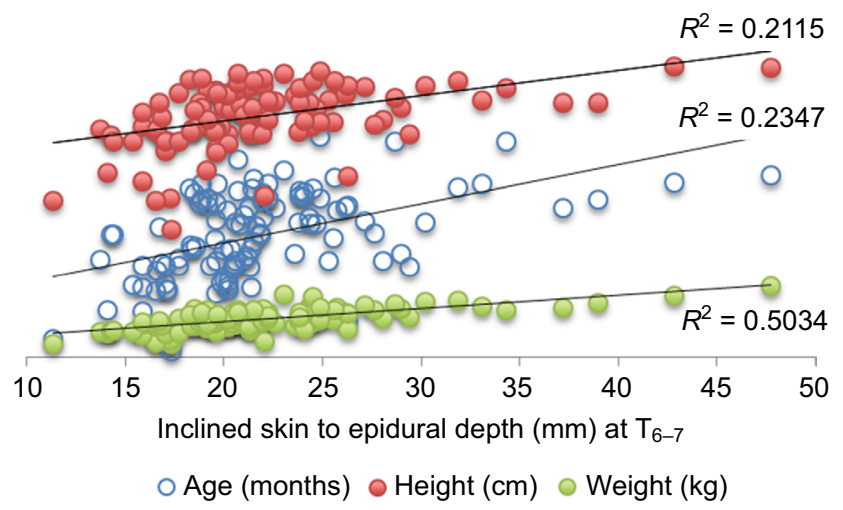

Figure 3 Linear correlation of age, height, and weight with straight skin to epidural depth at $\mathrm{T}_{6-7}$.
Over the various ages, $\mathrm{T}_{6-7}$ straight varied from 8.9 to $35.9 \mathrm{~mm}$ and $\mathrm{T}_{9-10}$ straight varied from 10.3 to $28.9 \mathrm{~mm}$; $\mathrm{T}_{6-7}$ inclined varied from 11.4 to $47.7 \mathrm{~mm}$ and $\mathrm{T}_{9-10}$ inclined varied from 10.9 to $41 \mathrm{~mm}$ (Figure 5). The incline to straight ratios at $\mathrm{T}_{6-7}$ and $\mathrm{T}_{9-10}$ swere $1.1 \pm 0.1(0.9-15)$ and $1.1 \pm 0.09$ (1.0-1.4), respectively.

\section{Discussion}

Information regarding the depth from the skin to the thoracic epidural depth may be a useful adjunct to the clinician and may help minimize complications during placement of neuraxial catheters. Although clinical experience has demonstrated the safety of the direct placement of an epidural catheter at the thoracic level, complications may occur including inadvertent entry into the intrathecal space and rarely neurologic damage. ${ }^{19}$ Deep insertion of a needle beyond the distance to the epidural space may theoretically lead to inadvertent trauma to the spinal cord, nerve roots, or entry into the intrathecal space. These issues may be further compounded when supervising trainees as there is no direct tactile sensation available as the soft tissue and ligaments are entered. Knowing the distance to the epidural space so that excessive needle entry is avoided may prevent such issues.

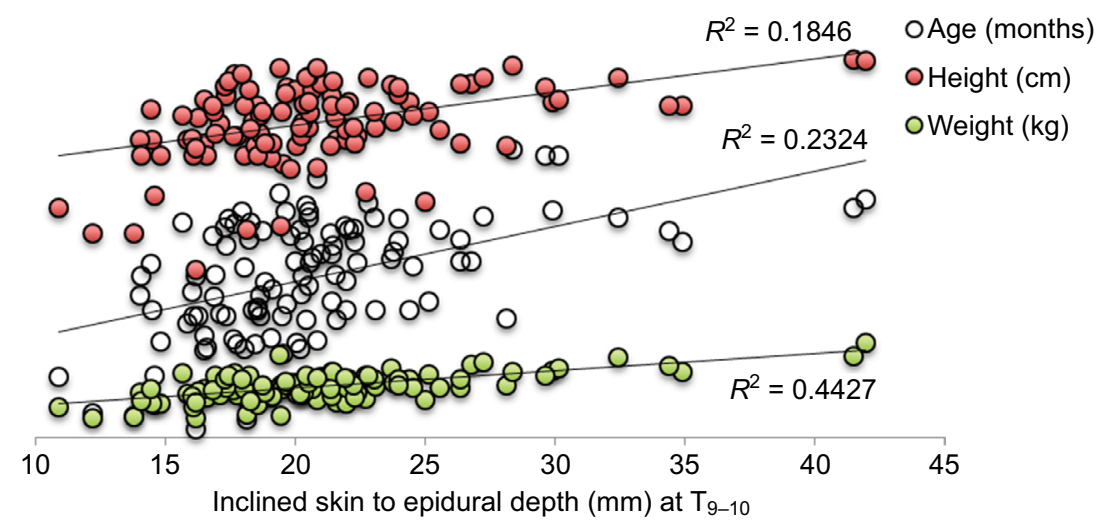

Figure 4 Linear correlation of age, height, and weight with inclined skin to epidural depth at $T_{9-10}$.

Table 4 Multivariate regression effects on $T_{6-7}$ inclined and $T_{9-10}$ inclined SEDs

\begin{tabular}{llllllll}
\hline Level & Parameter & Coefficient & SE & t & P-value & $\begin{array}{l}\text { 95\% Confidence } \\
\text { interval }\end{array}$ \\
\cline { 3 - 7 } & & & & & & Lower \\
\hline $\mathrm{T}_{6-7}$ inclined & Age & 0.056 & 0.033 & 0.505 & 0.615 & -0.048 & 0.081 \\
& Height & -0.389 & 0.056 & -3.034 & 0.003 & -0.283 & -0.059 \\
& Weight & 0.985 & 0.153 & 8.335 & 0.000 & 1.0 & 1.579 \\
$\mathrm{~T}_{9-10}$ inclined & Age & 0.136 & 0.032 & 1.148 & 0.254 & -0.027 & 0.100 \\
& Height & -0.415 & 0.055 & -3.042 & 0.003 & -0.277 & -0.058 \\
& Weight & 0.903 & 0.150 & 7.18 & 0.000 & 0.778 & 1.372 \\
\hline
\end{tabular}

Abbreviations: SEDs, skin to epidural depth; SE, standard error. 


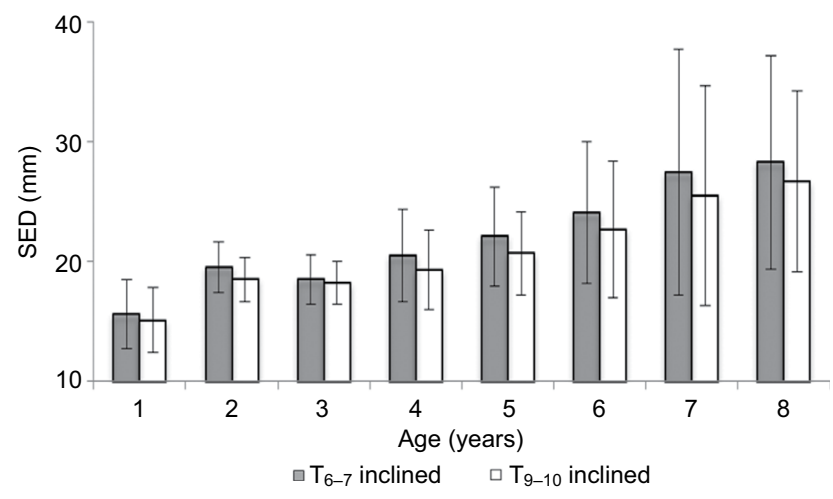

Figure 5 Comparison of the skin-to-epidural distance (SED) at $T_{6-7}$ and $T_{9-10}$ (inclined).

The present study using MRI is the first effort at defining the SED in children at two specific thoracic levels $\left(\mathrm{T}_{6-7}\right.$ and $\left.\mathrm{T}_{9-10}\right)$ and deriving a relationship between the straight and the inclined SEDs at these levels. The data demonstrate that although there was a relationship between SED with age, height, and weight, the correlation was greatest with weight. Formulae for the calculation of the SED at the thoracic level in children have been previously suggested. ${ }^{20}$ Masir et al reported a linear relation between the SED and the weight in a clinical study of 61 children. The formula devised by Masir et $\mathrm{al}^{20}(\mathrm{SED}=1.95+[0.045 \times \mathrm{kg}])$ does not appear to be applicable to small children as the fixed constant of $1.95 \mathrm{~cm}(19.5 \mathrm{~mm})$ used in their calculation is greater than the mean SED in the younger children ( $\leq 4$ years of age) in our study. The formula that we devised has a smaller fixed constant of $0.7 \mathrm{~cm}(7 \mathrm{~mm})$ that is applicable to children of all ages. The discrepancy between the two formulae can be explained by the differences in the cohorts of the two studies with the mean age of our study being 51.4 months with a weight of $16.3 \mathrm{~kg}$ compared to 61.6 months with $19.7 \mathrm{~kg}$ in the study of Masir et al. The smaller SED at lower thoracic intervertebral spaces observed in their study is similar to our findings; however, the wide interindividual variability observed by Masir et al was not seen in our study.

To our knowledge, this is the first study using MRI to evaluate the SED at the thoracic level in the pediatric population. Franklin et a $1^{15}$ used MRI to evaluate the SED in 70 children aged $<6$ years at the lumbar level and derived a formula for estimation of the SED. Their weight-based formula for lumbar SED $(\operatorname{SED}[\mathrm{mm}]=9.00+0.62 \times \mathrm{kg})$ is comparable to our predictive formula for thoracic SED
$\left(\left[\mathrm{T}_{6-7}\right.\right.$ inclined $\left.]=7.00+0.9 \times \mathrm{kg}\right)$. The fixed constant in our predictive formula closely resembles that of the Franklin et al's formula.

One of the challenges confronted when attempting to measure the SED is that the distance will be affected by the needle angle with an increased SED noted as the angle decreases to $<90^{\circ}$ to the skin. Although straight distances may be applicable when ultrasound is used to guide epidural catheter placement especially at the lumbar interspaces, a more acute angle is commonly used at the thoracic level. Kil et al $^{21}$ reported a significant correlation between ultrasound-guided prepuncture measurements and the actual SED for lumbar epidural catheter placement. However, as the usual entry line into the thoracic epidural space is more inclined than the lumbar approach, a direct correlation would not be expected with ultrasoundguided measurements. In the current study using MRI, a constant ratio of 1.1 was observed between inclined and straight SEDs at each level. This ratio may be helpful in calculating the inclined depth from the ultrasound-measured perpendicular depth.

One drawback of the current study is the limited study cohort size. Subsequent clinical validation with future trials to add additional patients will be of value in predicting the accuracy of the formulas derived from this study. One of the major limitations of the current study is that all of the patients were studied in the supine position while epidural catheter placement is performed in either the sitting or lateral decubitus position. To date, there are limited data regarding changes in the SED with changes in positioning. In a study of 10 young, healthy female volunteers, the SED did not change when measured using MRI in the flexed and neutral positions. $^{22}$

\section{Conclusion}

The main advantage of the present study is that the measurements are based on MRI measurements, which is accepted as the most accurate imaging technology available. While meticulous attention to placement technique, provider experience, and proper equipment for thoracic epidural catheter placement is mandatory, the proposed arithmetic calculation may aid anesthesiologists by providing an estimation of the SED. This information may facilitate accurate needle placement and decrease the risk of complications. The data derived from the current study need subsequent clinical validation with a clinical study comparing the calculated versus the actual SED. 


\section{Acknowledgment}

This investigation was performed without funding.

\section{Author contributions}

All authors contributed toward data analysis, drafting and critically revising the paper and agree to be accountable for all aspects of the work.

\section{Disclosure}

The authors report no conflicts of interest in this work.

\section{References}

1. Williams DG, Howard RF. Epidural analgesia in children. A survey of current opinions and practices amongst UK pediatric anesthetists. Paediatr Anaesth. 2003;13(9):769-776.

2. Ecoffey C, Lacroix F, Giaufre E, Orliaguet G, Courreges P. Epidemiology and morbidity of regional anesthesia in children: a followup one year prospective survey of the French-Language Society of Paediatric Anaesthesiologists (ADARPEF). Paediatr Anaesth. 2010;20(12):1061-1069.

3. Tobias JD, Lowe S, O'Dell N, Holcomb GW. Thoracic epidural anesthesia in infants and children. Can J Anaesth. 1993;40(9):879-882.

4. Bosenberg A, Hadley LG. Oesophageal atresia: caudo-thoracic epidural anesthesia reduces the need for postoperative ventilator support. Pediatr Surg Int. 1992; 7:289-291.

5. McNeely JK, Farber NE, Rusy LM, Hoffman GM. Epidural analgesia improves outcome following pediatric fundoplication. A retrospective analysis. Reg Anaesth. 1997;22(1):16-23.

6. Kirsch JR, Diringer MN, Borel CO, Hanley DF, Merritt WT, Bulkley GB. Preoperative lumbar epidural morphine improves postoperative analgesia and ventilatory function after transsternal thymectomy in patients with myasthenia gravis. Crit Care Med. 1991;19(12):1474-1479.

7. Liu SS, Block BM, Wu CL. Effects of perioperative central neuraxial analgesia on outcome after coronary artery bypass surgery: a metaanalysis. Anesthesiology. 2004;101(1):153-161.

8. Hodgson RE, Bosenberg AT, Hadley LG. Congenital diaphragmatic hernia repair-impact of delayed surgery and epidural analgesia. SAfr J Surg. 2000;38(2):31-34.
9. Koganaei H, Nakaoji T, Owaki A, Suzuki G. Paediatric anaesthesia and stress response. Masui. 1995;44(4):553-559.

10. Wolf AR, Doyle E, Thomas E. Modifying infant stress responses to major surgery: spinal vs. extradural vs opioid analgesia. Paediatr Anaesth. 1998;8(4):305-311.

11. Hasan MA, Howard RF, Lloyd-Thomas AR. Depth of epidural space in children. Anaesthesia. 1994;49(12):1085-1087.

12. Shenkman $Z$, Rathaus $V$, Jedeikin $R$, et al. The distance from the skin to the subarachnoid space can be predicted in premature and formerpremature infants. Can J Anaesth. 2004;51(2):160-162.

13. Adachi YU, Sano H, Sanjo Y, et al. The depth of epidural space in clinical practice - analysis of 4964 cases. Eur J Anaesthesiol. 2006;23: $11-15$.

14. Carnie J, Boden J, Smith FG. Prediction by computerized tomography of distance from skin to epidural space during thoracic epidural insertion. Anaesthesia. 2002;57(7):701-704.

15. Franklin AD, Lorinc AN, Shotwell MS, Greene EB, Wushensky CA. Evaluation of the skin to epidural and subarachnoid space distance in young children using magnetic resonance imaging. Reg Anesth Pain Med. 2015;40(3):245-248.

16. Kliewer MA, Gray L, Paver J, et al. Acute spinal ligament disruption: MR imaging with anatomic correlation. J Magn Reson Imaging. 1993; 3(6):855-861.

17. Zhuge W, Ben-Ghalim P, Hipp JA, Reitman C. Efficacy of MRI for assessment of spinal trauma: correlation with intraoperative findings. J Spinal Disord Tech. 2015;28(4):147-151.

18. Parizel PM, van der Zijden T, Gaudino S, et al. Trauma of the spine and spinal cord: imaging strategies. Eur Spine J. 2010;19(suppl 1):S8-S17.

19. Meyer MJ, Krane EJ, Goldschneider KR, Klein NJ. Case report: neurological complications associated with epidural analgesia in children: a report of 4 cases of ambiguous etiologies. Anesth Analg. 2012; 115(6):1365-1370.

20. Masir F, Dreiessen JJ, Thies KC, Winjen MH, Egmond JV. Depth of the thoracic epidural space in children. Acta Anaesthesiol Belg. 2006; 57(3):271-275.

21. Kil HK, Cho JE, Wo K, Koo BN, Han SW, Kim JY. Prepuncture ultrasound-measured distance: an accurate reflection of epidural depth in infants and small children. Reg Anesth Pain Med. 2007;32(2): 102-106.

22. Capogna G, Celleno D, Simonetti C, Lupoi D. Anatomy of the lumbar epidural region using magnetic resonance imaging: a study of dimensions and a comparison of two postures. Int J Obstet Anesth. 1997;6(2):97-100.
Journal of Pain Research

\section{Publish your work in this journal}

The Journal of Pain Research is an international, peer reviewed, open access, online journal that welcomes laboratory and clinical findings in the fields of pain research and the prevention and management of pain. Original research, reviews, symposium reports, hypothesis formation and commentaries are all considered for publication.

\section{Dovepress}

The manuscript management system is completely online and includes a very quick and fair peer-review system, which is all easy to use. Visit http://www.dovepress.com/testimonials.php to read real quotes from published authors. 